Research Article

\title{
Research on Deformation and Failure Evolution of Deep Rock Burst Drivage Roadway Surrounding Rock under Dynamic Disturbance
}

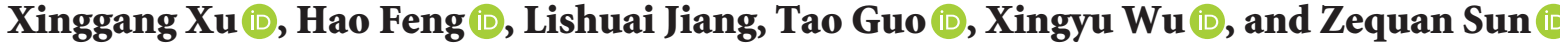 \\ State Key Laboratory of Mining Disaster Prevention and Control, Shandong University of Science and Technology, \\ Qingdao 266590, China \\ Correspondence should be addressed to Hao Feng; fh1244950367@163.com
}

Received 20 July 2021; Accepted 5 October 2021; Published 29 October 2021

Academic Editor: Shan Gao

Copyright ( 2021 Xinggang Xu et al. This is an open access article distributed under the Creative Commons Attribution License, which permits unrestricted use, distribution, and reproduction in any medium, provided the original work is properly cited.

In order to explore the deformation and failure evolution characteristics of the surrounding rock during the connection process of the deep rock burst drivage roadway under the dynamic load disturbance, and based on this, the catastrophe mechanism of the roadway is analyzed, taking the rock burst accident of Longyun Coal Industry in Shandong Province on October 20, 2018, as the engineering background. FLAC3D was used to study the distribution evolution law of displacement, plastic zone, and stress field in the whole process of "Roadway Drivage-Deformation and Failure-Instability and Disaster" in the surrounding rock of deep roadway. The research results show that under the conditions of high stress and dynamic load disturbance, the surrounding rock deformation and failure are significant during the connection of the thick-top-coal roadway in deep, the roof is the most, the two ribs are the second, and the roadway top-coal is in an "inverted trapezoid" sag pattern. When the length of the bolts is limited or the anchoring force of the cables is not enough to effectively restrain the roof, the impact of dynamic disturbance on the plastic damage of the roof is greater than that of the two ribs and the floor, and the plastic damage of the coal seam roof affecting the surrounding rock deformation of the roadway drivage played a leading role.

\section{Introduction}

With the increasing depletion of shallow coal resources, coal mining depth, scope, and intensity continue to increase in China, and deep mining will become the norm in the development of coal resources in the future [1]. However, the depth of roadways has increased daily; the conditions such as high stress, strong dynamic disturbance, and soft and broken surrounding rocks have become more complex. These development trends have an adverse effect on the roadway drivage and stability of surrounding rock, inducing severe dynamic disasters easily such as roof caving and rock burst. In recent years, the number of rock burst mines in China has been increasing. As of June 2019, there are 121 mines in production and identified as rock burst mines, which are widely distributed in 14 provinces, cities, and autonomous regions [2]. Studies have shown that about $85 \%$ of rock bursts occur in the roadway, and due to the disturbance of the external seismic source, the surrounding rock of the roadway produces dynamic damage under the static-dynamic coupling loads [3-7]. Particularly in the environment of high stress, the roadway is more prone to deformation and instability under dynamic load disturbance [8], which seriously threatens the safe and efficient production of coal mines.

Domestic and international scholars have conducted indepth researches on the abovementioned problems. In terms of laboratory tests, Wang et al. [9] used the self-developed similar simulation test facility for bolting support roadway under static-dynamic coupling loading to study the failure law of bolting support roadway under dynamic load. Zhang et al. [10] analyzed the change law of surrounding rock under the influence of mining through similar simulation test. Li et al. [11] analyzed the failure characteristics of the 
floor under mining dynamic load through similar simulation test. Ning et al. [12] studied the deformation and failure characteristics of deep surrounding rock of chamber under dynamic load disturbance through similar material simulation tests. Hence, carrying out the mechanical response test of rock and similar material models under dynamic load can provide basic research results for the stability control of surrounding rock of dynamic pressure roadway, which has important guiding significance. Kang et al. [13, 14] pointed out that the study of surrounding rock control spans multiple orders of magnitude on the spatial scale. The research contents and methods of different scales are different, and the interrelation between different scales is very important. Meanwhile, Zhu et al. [15] believe that numerical simulation is an important means to push the theoretical model obtained from laboratory test scale to engineering application. It can be seen that engineering scale numerical simulation, which can reflect the engineering geological conditions more truly, is an important way to apply the results of experiments and theories to solve practical problems in the locale.

In terms of engineering scale numerical simulation, Gao et al. [16] used FLAC to conduct numerical analysis on the mechanical response of surrounding rock under dynamic disturbance and studied the variation of stress field, displacement field, and plastic zone of surrounding rock under dynamic disturbance. Li et al. [6] used particle flow software PFC2D to carry out numerical calculation on the stability of high stress roadway under dynamic load. Wang et al. [17] used RFPA numerical software to simulate the dynamic response law of surrounding rock under different disturbance intensities. Tang et al. [18, 19] used finite element software ABAQUS to conduct numerical analysis on the mechanical response of surrounding rock of roadway with interlayer under the influence of stope blasting. Yuan et al. [20] used FLAC3D to conduct a numerical study on the form characteristics and evolution laws of surrounding rock plastic zone in deep dynamic pressure mining roadway. $\mathrm{Wu}$ et al. [21] established a plane strain model with FLAC3D, and analyzed the dynamic load response characteristics of anchoring surrounding rock under impact load. Jiao et al. $[22,23]$ used FLAC3D to establish a plane strain numerical model of the anchoring surrounding rock under the staticdynamic coupling loading and analyzed the dynamic load response characteristics and impact failure process of the anchoring bearing structure. Li et al. [24] used the numerical software $3 \mathrm{DEC}$ to simulate the cyclical excavation and calculate the stress and displacement evolution law of the floor under the dynamic disturbance of the instability of voussoir beam structure in deep mining. Jing et al. [25] took the rock burst accident of Longyun Coal Industry as the engineering background, based on the particle flow software PFC2D simulated the mesostructure evolution process of rock burst roadway under the coupling action of high stress and dynamic disturbance. The above research results are of great significance for the control of deep roadway surrounding rock and the prevention of dynamic disasters. However, most of the numerical models are two-dimensional models or three-dimensional plane strain models, which ignore the influence of engineering disturbances such as step-by-step roadway advancing and step-by-step mining of working face on the stress field of roadway surrounding rock. Moreover, rock burst in deep mining roadway is mostly influenced by the superposition of mining disturbance and external dynamic load disturbance; therefore, the whole evolution process of "Roadway Drivage-Deformation and Failure-Instability and Disaster" caused by surrounding rock under the combined action of both should be fully considered.

Based on the existing research results, this paper takes the No. 3 connection roadway of drainage roadway at panel 1303 in the "10.20" Rock Burst Accident of Longyun Coal Industry as the engineering background. By using the finite difference numerical simulation method of engineering scale, the deformation and failure evolution of surrounding rock under the superposition of mining disturbance and external dynamic load, and the mechanism of instability causing the disaster are deeply studied through the detailed simulation of the process of roadway formation in the accident roadway and the application of dynamic load. The research methods and results can provide an important basis for research in related fields.

\section{Project Case of Rock Burst Drivage Roadway}

\subsection{Engineering Geology Overview of Longyun Coal Industry.} Longyun Coal Industry is located in the northeast of Yuncheng County, Shandong Province, China. The No. 3 coal seam is the main and first mining coal seam. The occurrence state of coal seam is relatively stable, with an average thickness of $6.93 \mathrm{~m}$ and a buried depth of about $1035 \mathrm{~m}$. The No. 3 coal seam has the characteristics of a composite roof. The roof is mainly mudstone, sandy mudstone, and fine sandstone. The overall strength of the roof is low. The immediate roof is sandy mudstone with a thickness of $2.12 \mathrm{~m}$, the main roof is composed of argillaceous sandstone and fine sandstone with a total thickness of $8.88 \mathrm{~m}$, the immediate floor is sandy mudstone with a thickness of $1.07 \mathrm{~m}$, and the main floor is fine sandstone with a thickness of $2.94 \mathrm{~m}$. The generalized geological column about roof and floor of panel 1303 is shown in Figure 1. According to the impact tendency identification, the No. 3 coal seam and its floor rock have a weak impact tendency, and the roof rock has a strong impact tendency [26].

The strata of panel 1303 strike near the north, and the overall shape is high in the west and low in the east. Affected by the surrounding faults, local coal seams may have certain undulating changes, forming relatively wide and gentle small folds. At the turning end of the folds, fractures in the coal seam and roof will develop, and the coal seam will be broken. Relationship of the roadway in panel 1303 is illustrated in Figure 2.

2.2. Overview of Roadway Support Technology. The No. 3 connection roadway of drainage roadway at panel 1303 is excavated along the floor, and the full section is excavated at one time. The designed rectangular section has a 


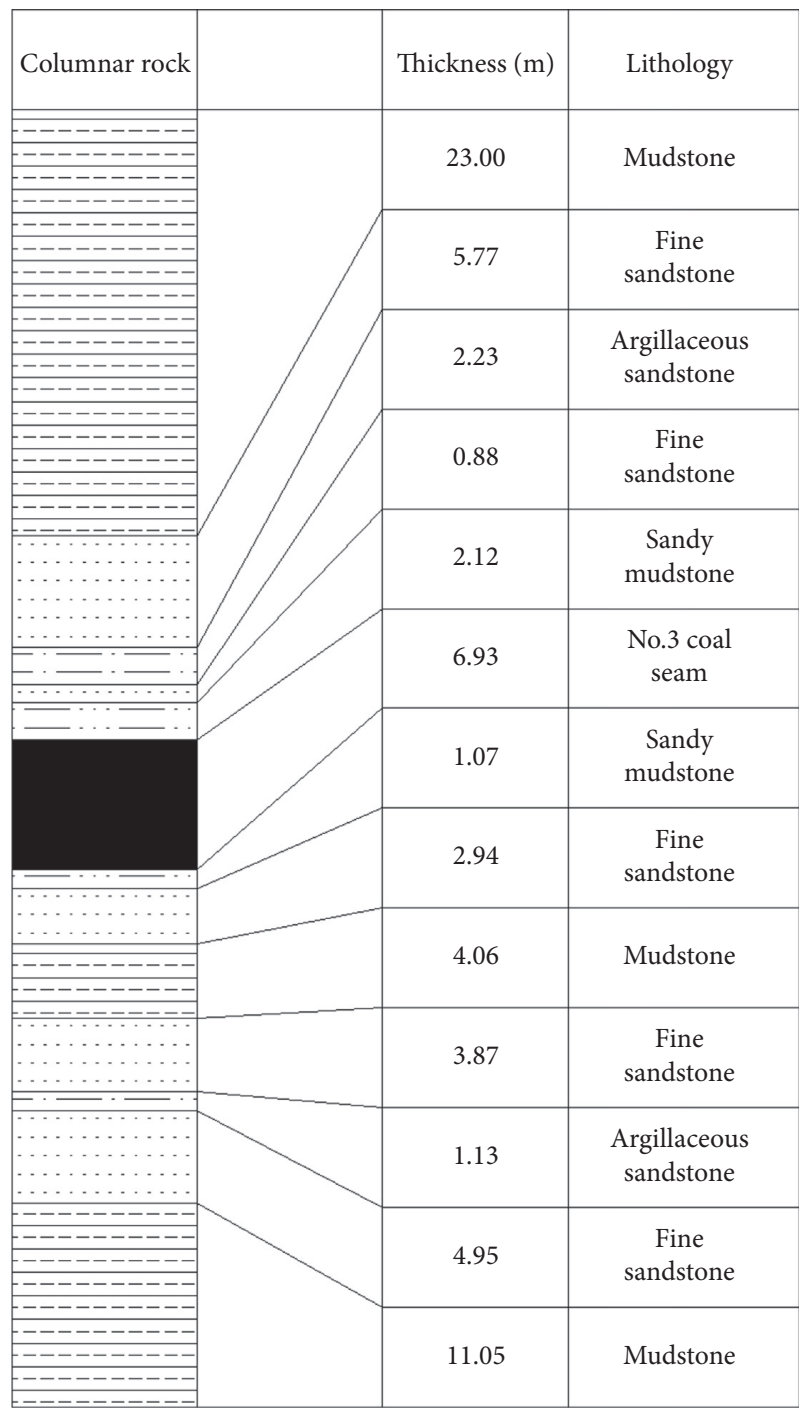

Figure 1: Generalized geological column of panel 1303.

width $\times$ height of $5.2 \mathrm{~m} \times 4.0 \mathrm{~m}$, and a coal seam of about $3 \mathrm{~m}$ is left on the roof. The roadway is supported by cable bolts, rebar bolts, anchor beams, and W-steel tape [27]. The roof is supported by high-strength rebar bolts, the spacing between rows is $800 \mathrm{~mm} \times 1000 \mathrm{~mm}$, and the size of the square tray is $150 \mathrm{~mm} \times 150 \mathrm{~mm} \times 10 \mathrm{~mm}$. The roof cable bolts use steel strands, with a row spacing of $2000 \mathrm{~mm} \times 1000 \mathrm{~mm}$, and U29 anchor beams are used as the top beams between the cable bolts. The two ribs use rebar bolts, with a row spacing of $750 \mathrm{~mm} \times 1000 \mathrm{~mm}$, and the size of the W-steel tape is $1900 \mathrm{~mm} \times 280 \mathrm{~mm} \times 5 \mathrm{~mm}$. The two ribs cable bolts use steel strands, with a row spacing of $2100 \mathrm{~mm} \times 2000 \mathrm{~mm}$. The specific support parameters are shown in Figure 3.

2.3. Overview of the Rock Burst Accidents. At 22:37 on October 20, 2018, a serious rock burst occurred during the connection of the No. 3 connection roadway and the drainage roadway at panel 1303 in the south of the first mining section of Longyun Coal Industry No. 3 coal seam. It caused varying degrees of damage to the $348 \mathrm{~m}$ roadway,

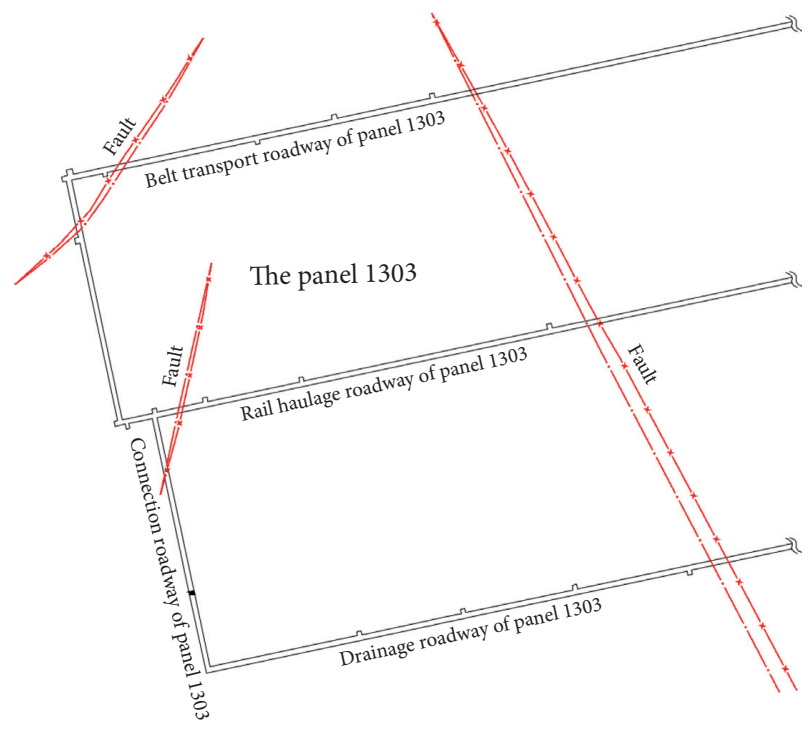

FIGURE 2: Layout sketch of panel 1303.

severely damaged the $198 \mathrm{~m}$ section, and killed 21 miners. The accident area and roadway damage are shown in Figure 4 .

Before the accident, on September 29, the straight-line distance between the heading face of the No. 3 connection roadway and the 1303 drainage roadway was $158 \mathrm{~m}$, and the drivage was stopped at about $174 \mathrm{~m}$ from top to bottom. The connection distance between the No. 3 connection roadway from bottom to top and the heading face that stopped drivage was only $3 \mathrm{~m}$. At the time of the accident, the excavator was in a stopped state, and the bolting support for the heading face had been completed. The microseismic monitoring system showed a vibration event with energy of $1.2 \times 10^{6} \mathrm{~J}$ at $61 \mathrm{~m}$ north of the intersection point of haulageway and the No. 3 connection roadway of panel 1303 . However, the buried depth of the accident roadway was $1027 \sim 1067 \mathrm{~m}$. Under the action of high in situ stress, the high elastic energy accumulated in the surrounding coal and rock was close to the limit. Even the slight drivage disturbance or the far-field source dynamic load can cause the stress equilibrium state to be broken and the high elastic energy to be released suddenly, leading to the dynamic disaster of roof caving or rock burst in the heading face.

After the occurrence of rock burst, the scene investigation showed that there was a failure area of $84 \mathrm{~m}$ behind the stop heading face of the No. 3 connection roadway; meanwhile, the cable bolts, rebar bolts, and anchor beams showed different forms of distortion and cracking, and the roadway roof obviously subsided and the two ribs converged. The damage of roadway in accident area is shown in Figure 4. The roadway at the A-A section has a width of $3.44 \mathrm{~m}$ and a height of $2.16 \mathrm{~m}$. It was found that individual cable bolts were broken, the anchor beams were cracked, the rebar bolts were suspended from the roof but not broken, and individual rebar bolts were struck whole into the roof. The $74 \mathrm{~m}$ roadway behind the heading face of the No. 3 connection roadway was a severely damaged area. The two ribs of the B-B section converged to $1.5 \sim 2.0 \mathrm{~m}$, the roof sag 


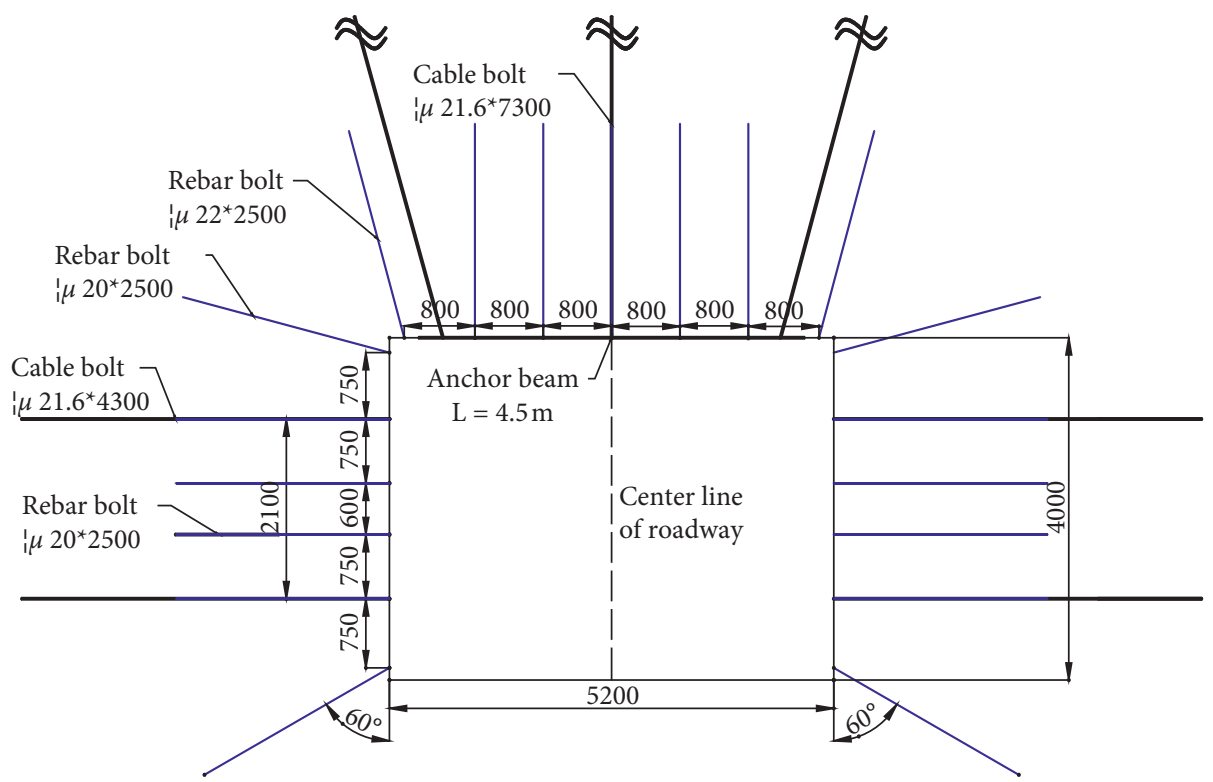

FIGURE 3: Support design of connection roadway of panel 1303.

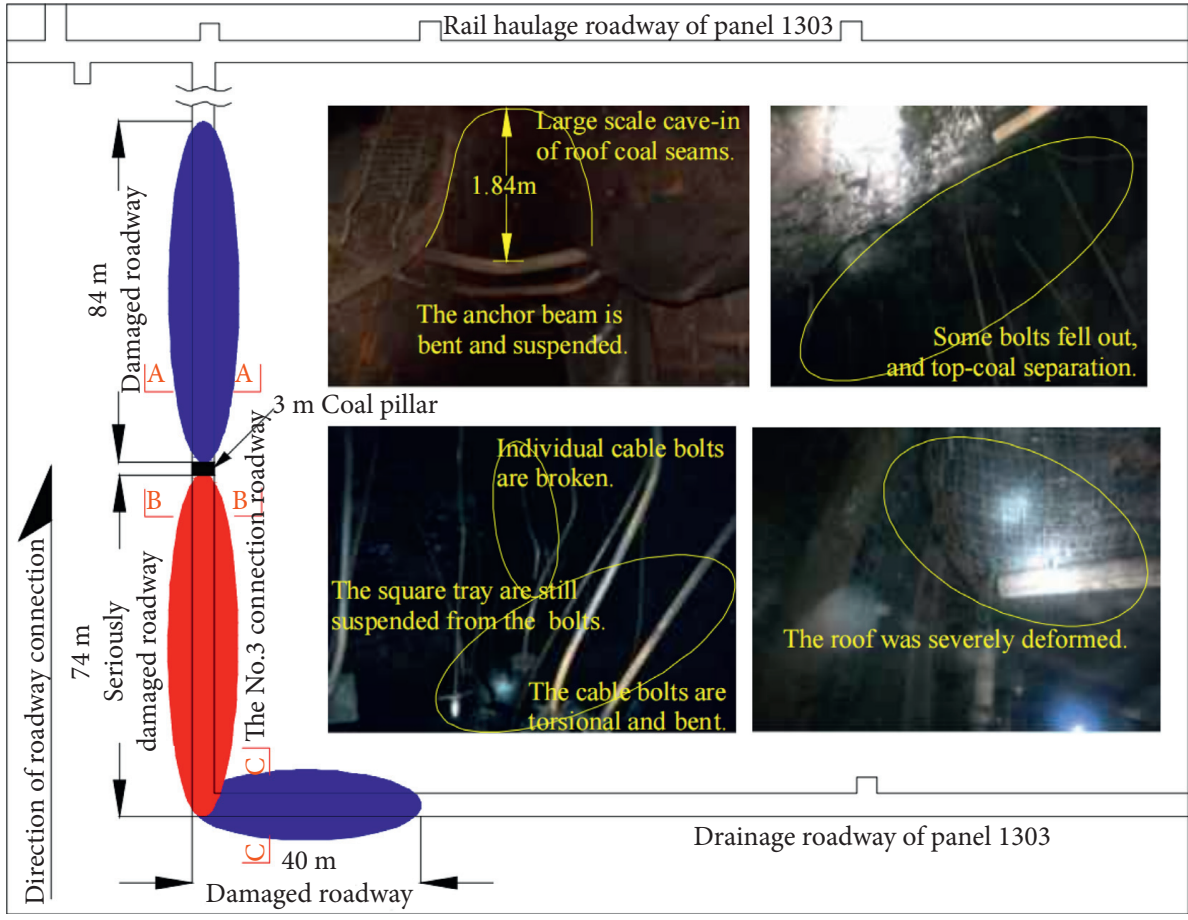

Figure 4: Accident area and roadway damage.

$1.0 \sim 2.5 \mathrm{~m}$, the anchor beams were bent and sag seriously, the roof near the excavator was broken, and the roadway was deformed seriously. There was a $40 \mathrm{~m}$ damaged area in the drainage roadway at panel 1303 . The roof at the $\mathrm{C}-\mathrm{C}$ section collapses to the immediate roof of the No.3 coal seam, the two ribs converged, and part of the roof anchor beams was bent and suspended; meanwhile, the roof cable bolts and rebar bolts were still suspended from the roof; there were individual cable bolts and rebar bolts that were broken.

\section{Deformation and Failure Evolution of Surrounding Rock under Dynamic Disturbance}

In order to perform an in-depth study of the "Roadway Drivage-Deformation and Failure-Instability and Disaster" evolution mechanism of the rock burst drivage roadway surrounding rock under dynamic disturbance, this paper uses FLAC3D to extract the deformation and plastic failure 
data of the roadway surrounding rock under static and dynamic load disturbances and analyzes the distribution and evolution characteristics of the displacement, plastic zone, and stress field in the roadway connection process specifically.

\subsection{Engineering Scale Numerical Model and Method.} According to the geological conditions of Longyun Coal Industry the No. 3 coal seam, FLAC3D simulation software is used to construct a three-dimensional numerical model, as shown in Figure 5(a). The model is $78.5 \mathrm{~m}$ long, $150 \mathrm{~m}$ wide, and $70 \mathrm{~m}$ high. The lithology parameters of the coal strata are taken from the rock burst accident area of Longyun Coal panel 1303, and the mechanical parameters are shown in Table 1. The model top boundary is loaded with a $24 \mathrm{MPa}$ vertical stress to simulate the overburden pressure by assuming that the overlying unit weight is $0.025 \mathrm{MN} / \mathrm{m}^{3}$, and no displacement is allowed in the direction perpendicular to the side boundaries. At the time of accident, there was the influence of drivage, mining disturbance, and slip of the nearby fault zone. Therefore, it is the key for numerical simulation of deformation and failure of coal roadway to reflect the disturbance reasonably in the model. References $[19,28,29]$ simulated the disturbance in the form of the input dynamic load disturbance wave and applied the horizontal dynamic load disturbance to the upper boundary of the model. The corresponding parameters can be obtained according to the microseismic monitoring system. The cable bolts and rebar bolts are regarded as structural elements. This type of element is embedded in FLAC3D to simulate roadway support. The support simulation is carried out according to the actual support plan on site, and the full section diagram of roadway support is shown in Figure 5(b).

The simulated roadway is excavated along with the No. 3 coal seam floors with a strike length of $150 \mathrm{~m}$. Because at the time of the accident, only $3 \mathrm{~m}$ coal pillars were left between the heading face and the stop heading face, there was an influence of the far-field seismic source at this time. Therefore, in order to accurately reflect the deformation and failure characteristics of the surrounding rock in the whole "Roadway Drivage-Deformation and Failure-Instability and Disaster" process, the simulated roadway is divided into five calculation cycles $((1) \sim(5))$ when the distance of drivage is $50 \mathrm{~m}$, and in the fifth calculation cycle (5), a dynamic load is applied to the upper boundary of the model, as shown in Figure 6. At the same time, a monitoring section is set in the middle of each calculation cycle, and a total of 110 monitoring points are set up on the No. 1 5 monitoring sections including the roof monitoring lines and the left-rib monitoring lines. The monitoring lines setting is shown in Figure 6. The simulation process is as follows. (1) After establishing the model, setting the mechanical parameters and boundary conditions, the calculation reaches the initial balance. (2) When $50 \mathrm{~m}$ away from the roadway connection, five calculation cycles ((1) (5)) are set to simulate the stepby-step excavation of the roadway. (3) The length of the first four steps is the same, which is $10 \mathrm{~m}$, and the length of the fifth step is $7 \mathrm{~m}$, leaving $3 \mathrm{~m}$ coal pillar between the heading face and the stop heading face. (4) The support follows each step of roadway excavation, set the support body and assign the mechanical parameters to calculate the model to balance, and then continue to the next calculation cycle after the balance. (5) The drivage stops when the roadway is excavated to a distance of $3 \mathrm{~m}$ from the connection position (the calculation cycle (5)). At this time, a dynamic load disturbance is applied to the upper boundary of the model. This study will analyze the deformation and failure distribution evolution characteristics of the monitoring stations on each monitoring section during the advancement of the heading face and reproduce the stress environment of the surrounding rock of the roadway before and after the impact.

\subsection{Deformation Evolution Law of Surrounding Rock under} Dynamic Load Disturbance. A large number of studies have shown that after entering deep mining, surrounding rock exhibits continuous deformation, large deformation, and serious damage under the high stress environment. Such characteristics are more prominent under the coupling action of high stress and dynamic load disturbance. The large deformation and failure mechanism of surrounding rock has always been the focus of research on safe deep mining of coal.

In order to explore the distribution characteristics and evolution of the surrounding rock displacement during the connection of deep rock burst drivage roadway under the dynamic load disturbance, the data processing and analysis of each group of monitoring stations on the monitoring section are carried out. On the No. 1 5 monitoring section at different distances through the roadway, the evolution of the roof displacement is shown in Figure 7, and the evolution of the left-rib displacement is shown in Figure 8. As can be seen from Figure 7, unlike the rotary or squeezing failure of the general deep roadway roof, the thick coal roof of the deep rock burst drivage roadway presents an "inverted trapezoidal" sag pattern. When the heading face advances to $3 \mathrm{~m}$ from the connection, the maximum roof sag increases from $539.4 \mathrm{~mm}$ to $748.6 \mathrm{~mm}$, and the roadway shoulder sag increases from $190.6 \mathrm{~mm}$ to $253.4 \mathrm{~mm}$. The analysis suggests that, for the deep coal roadways with significant large deformation characteristics, the edges of the two weak ribs also undergone large deformation and plastic failure and gradually expand to the deep part of the surrounding rock until a new balance is reached. In this process, the stress of the roof coal separation of the roadway was transferred to the two ribs of the roadway, causing stress concentration, and the position of the shoulder of the roadway also had a relatively obvious sag, which caused the roadway roof coal to show a significant overall sag. Furthermore, it is very easy to induce catastrophic damage such as roof fall and rock burst under the seismic source disturbance.

In order to more clearly see the characteristics of the displacement distribution of the roadway surrounding rock, combined with the analysis of the vertical stress cloud diagram and the displacement vector diagram of the surrounding rock on the monitoring section (as shown in Figure 9), it can be seen that the amount of roof sag is more 


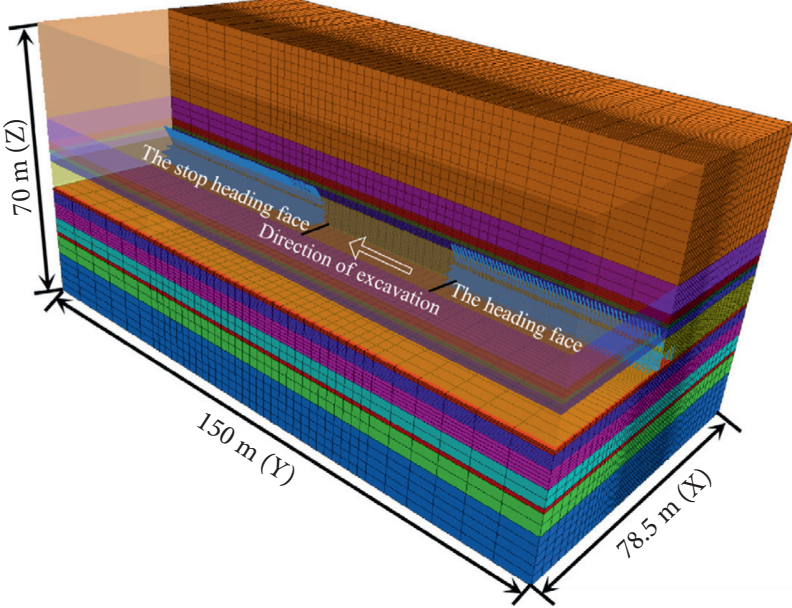

(a)

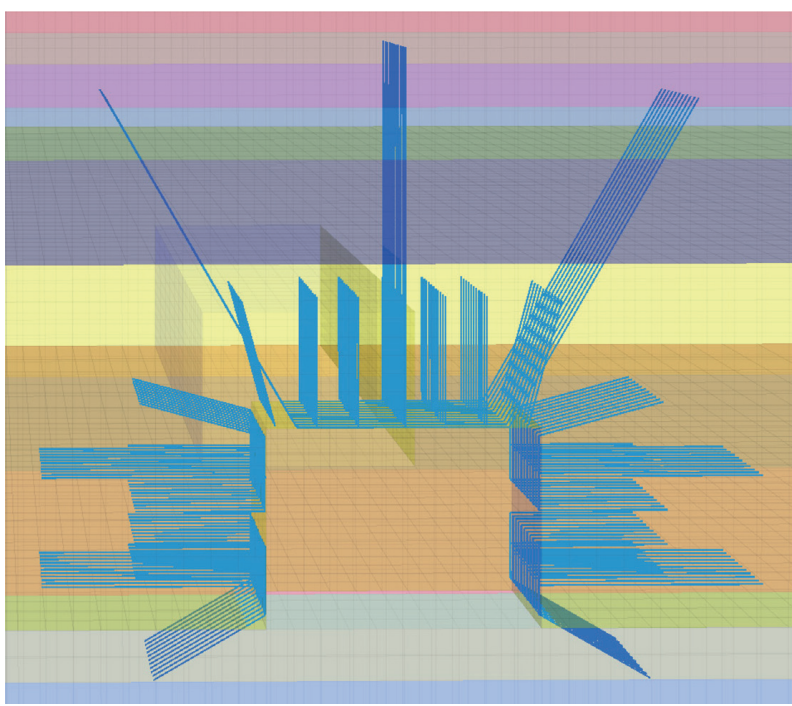

(b)

Figure 5: Numerical model. (a) Model size. (b) Roadway support.

TABLe 1: Mechanical parameters of rock mass.

\begin{tabular}{|c|c|c|c|c|c|c|}
\hline Lithology & $K(\mathrm{GPa})$ & $G(\mathrm{GPa})$ & $C(\mathrm{MPa})$ & $\varphi\left(^{\circ}\right)$ & $\gamma\left(\mathrm{kg} \cdot \mathrm{m}^{-3}\right)$ & $\sigma(\mathrm{MPa})$ \\
\hline Mudstone & 7.36 & 4.00 & 3.40 & 35 & 2724 & 2.20 \\
\hline Fine sandstone & 6.83 & 6.24 & 3.30 & 40 & 2700 & 4.19 \\
\hline Argillaceous sandstone & 5.00 & 4.00 & 3.26 & 37 & 2480 & 3.78 \\
\hline Fine sandstone & 6.83 & 6.24 & 3.30 & 40 & 2700 & 4.19 \\
\hline Sandy mudstone & 5.20 & 3.10 & 3.20 & 37 & 2657 & 2.20 \\
\hline Coal & 0.98 & 0.37 & 1.40 & 31 & 1450 & 0.30 \\
\hline Sandy mudstone & 5.20 & 3.10 & 3.20 & 37 & 2657 & 2.20 \\
\hline Fine sandstone & 6.83 & 6.24 & 3.30 & 40 & 2700 & 4.19 \\
\hline Mudstone & 7.36 & 4.00 & 3.40 & 35 & 2724 & 2.20 \\
\hline Fine sandstone & 6.83 & 6.24 & 3.30 & 40 & 2700 & 4.19 \\
\hline Argillaceous sandstone & 5.00 & 4.00 & 3.26 & 37 & 2480 & 3.78 \\
\hline Fine sandstone & 6.83 & 6.24 & 3.30 & 40 & 2700 & 4.19 \\
\hline Mudstone & 7.36 & 4.00 & 3.40 & 35 & 2724 & 2.20 \\
\hline
\end{tabular}

Note. $K$ is the bulk modulus; $G$ is the shear modulus; $c$ is the cohesion; $\varphi$ is the friction angle; $\gamma$ is the density; $\sigma$ is the tensile strength.

than the convergence between the two ribs and the amount of roadway floor heave. The abutment stress peaks of the deep coal and rock of the ribs on each monitoring section are 34.0 $\mathrm{MPa}$, 34.8 $\mathrm{MPa}$, 33.7 $\mathrm{MPa}, 34.4 \mathrm{MPa}$, and 39.7 $\mathrm{MPa}$, and the peak points are, respectively, $9.0 \mathrm{~m}, 7.6 \mathrm{~m}, 6.4 \mathrm{~m}, 6.8 \mathrm{~m}$, and $7.6 \mathrm{~m}$ from the coal wall. The ribs' convergences amount also shows a trend of first decreasing and then increasing. It can be considered that the support scheme played a certain role in the stability control of the surrounding rock before the roadway advances to $25 \mathrm{~m}$. After that, the displacement of the roof and the two ribs of the roadway increased again, and when the distance between the roadway and the coal pillar was only $3 \mathrm{~m}$, the maximum deformation of the roof and the two ribs under the dynamic load disturbance increased rapidly to $748.6 \mathrm{~mm}$ and $633 \mathrm{~mm}$, respectively.

Under normal circumstances, the roof of a deep coal roadway under high stress will expand, slide along the surface, and gradually bulge into the roadway, forming a "Vshaped" extrusion type deformation failure, but in this simulation experiment, the distribution of roof sag shows discontinuous sag, which is due to the large roof span of the roadway and the large distance between the bolts and cables, which results in the larger roof sag at the place where the ability of the cable bolts and rebar bolts to protect the surface is weak. It can be seen that the anchoring force, row spacing, and bolt surface protecting component are the factors that must be considered in the optimization of supporting design. In addition, the maximum horizontal displacement of the two ribs occurred in the upper middle of the coal rib, indicating that the coal mass at this location was severely broken due to the decompression of the roof separation, which in turn reduced its strong support for the roof coal seam.

3.3. Plastic Failure Evolution Law of Surrounding Rock under Dynamic Load Disturbance. The generation of plastic zone is the essential cause of the deformation and failure of the 


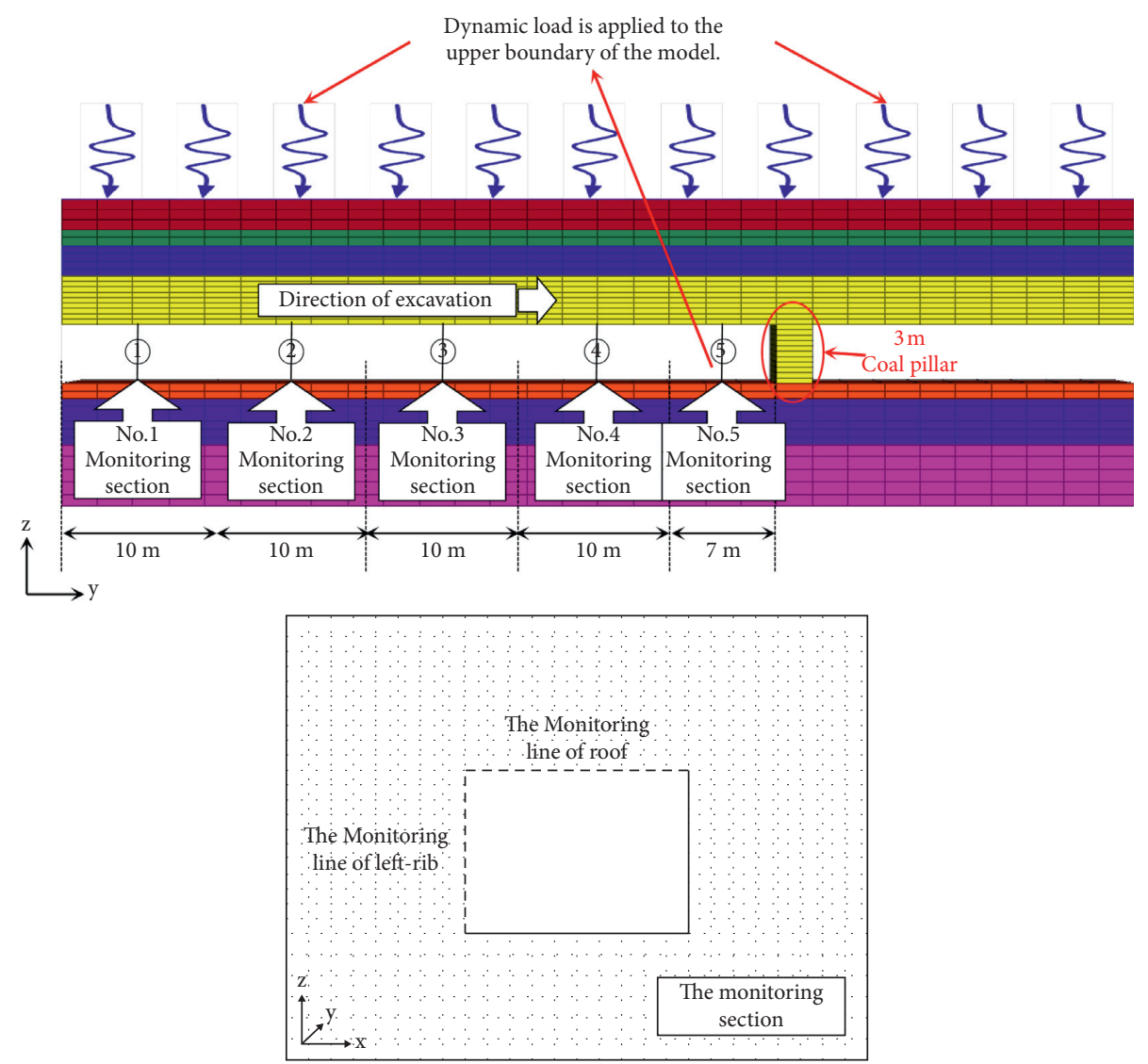

FIgURE 6: Numerical simulation of roadway excavation and the layout of roadway monitoring line.

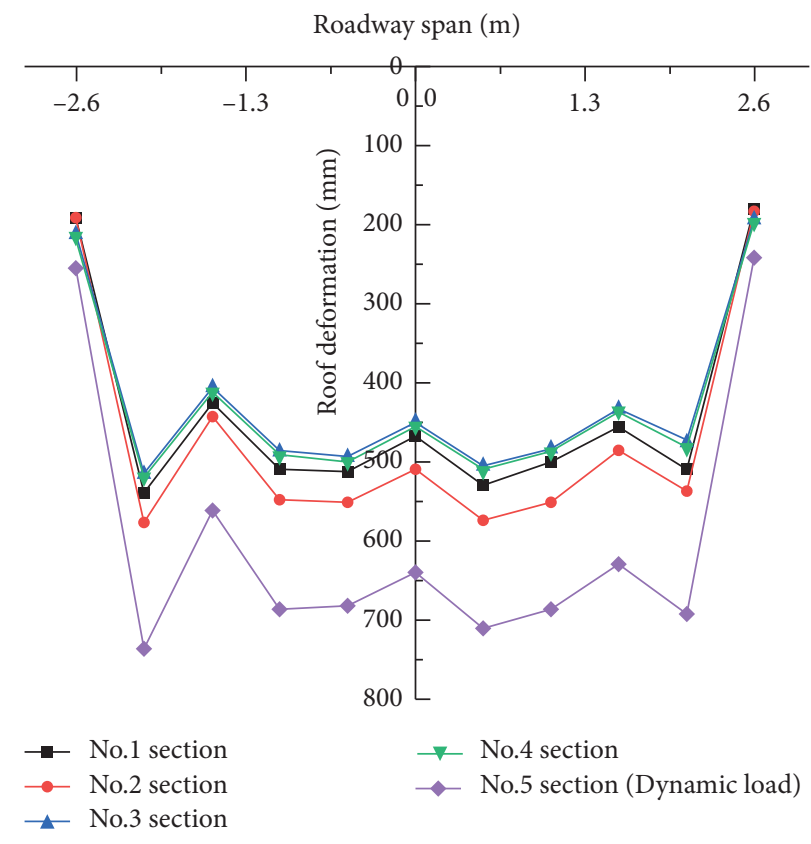

Figure 7: Evolution of roof displacement pattern.

surrounding rock. The distribution characteristics of the plastic zone are affected by many factors, and generally speaking, it is not uniformly distributed. The size of the plastic zone directly determines the failure form and extent of the roadway surrounding rock. By exploring the distribution and evolution characteristics of the plastic zone of the 


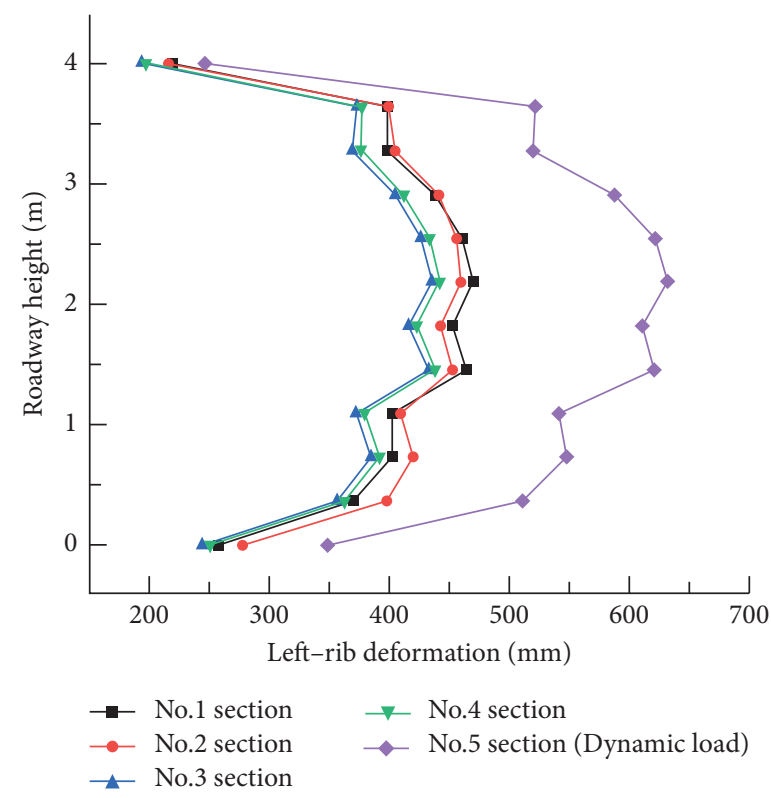

FIGURE 8: Evolution of left-rib displacement pattern.
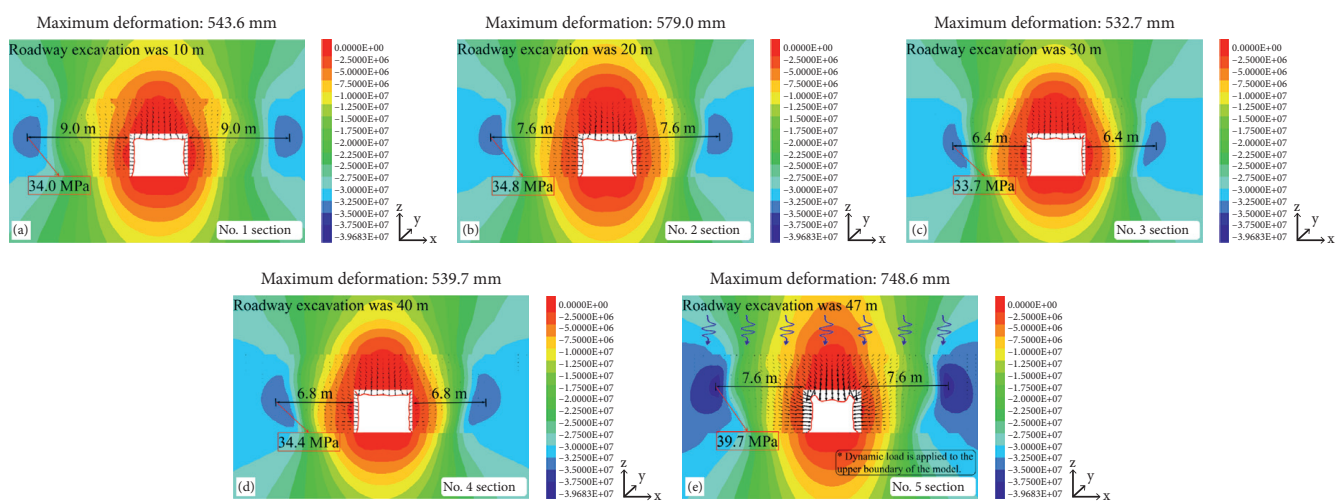

FIGURE 9: Distribution of surrounding rock stress and displacement during roadway excavation. Roadway excavation was (a) $10 \mathrm{~m}$, (b) $20 \mathrm{~m}$, (c) $30 \mathrm{~m},(\mathrm{~d}) 40 \mathrm{~m}$, and (e) $47 \mathrm{~m}$.

surrounding rock during the impact process of roadway advancing, it has important guiding significance for the engineering practice of surrounding rock stability control and rock burst prevention and control.

In order to explore the distribution characteristics and evolution law of plastic zone in surrounding rock during the connection period of deep rock burst drivage roadway under dynamic disturbance, the distribution of plastic zone on each monitoring section is shown in Figure 10. The distribution of the plastic zone on the horizontal section of the two ribs of coal and rock mass when the roadway is close to the connection is shown in Figure 11.

From the distribution of plastic zone in surrounding rock during roadway advancing (as shown in Figure 10), it can be visually seen that due to the superposition of deep high in situ stress static load and dynamic load disturbance, the instability and plastic failure of the roadway top-coal are caused by the large deformation of the roof surrounding rock directly. When the heading face advances to $10 \mathrm{~m}$ from the roadway connection, the width of the plastic zone of the coal seam is reduced from $7.4 \mathrm{~m}$ to $5.8 \mathrm{~m}$ under the support of the roadway surrounding rock, and the plastic failure in the roof and ribs is controlled. During the period, the support plan played a certain role in supporting the surrounding rock. When the heading face advances to $3 \mathrm{~m}$ away from the roadway connection, the plastic zone of the surrounding rock increases significantly, and the plastic failure zone of the roof coal expands most obviously, from $5.8 \mathrm{~m}$ to $7.5 \mathrm{~m}$, and the hard roof plastic failure zone of the roadway development and expand again. As shown in Figure 11(a), when the roadway is $10 \mathrm{~m}$ away from the roadway connection, it can be seen that the plastic zone at the two heading faces of the roadway has advanced connection, and the width of the plastic zone reaches $9.5 \mathrm{~m}$. As shown in Figure 11(b), when there is still $3 \mathrm{~m}$ from the roadway connection, it can be seen that the $3 \mathrm{~m}$ coal pillar between the two heading faces has been destroyed, and the width of the two ribs of the plastic failure range has reached $16.9 \mathrm{~m}$, 

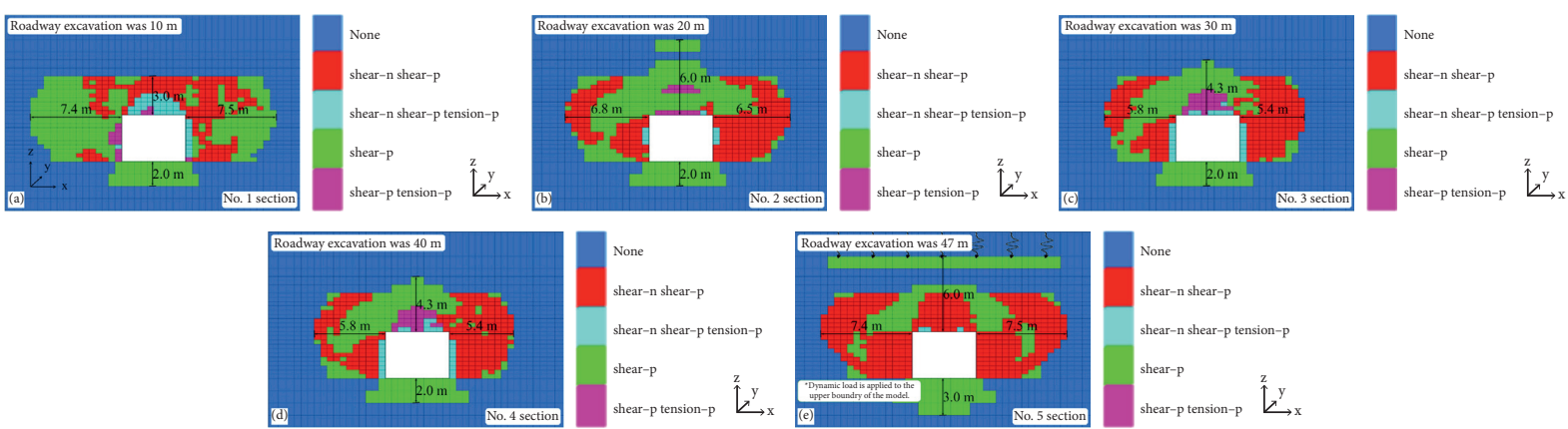

Figure 10: Distribution of surrounding rock plastic zone during roadway excavation. Roadway excavation was (a) $10 \mathrm{~m}$, (b) $20 \mathrm{~m}$, (c) $30 \mathrm{~m}$, (d) $40 \mathrm{~m}$, and (e) $47 \mathrm{~m}$.
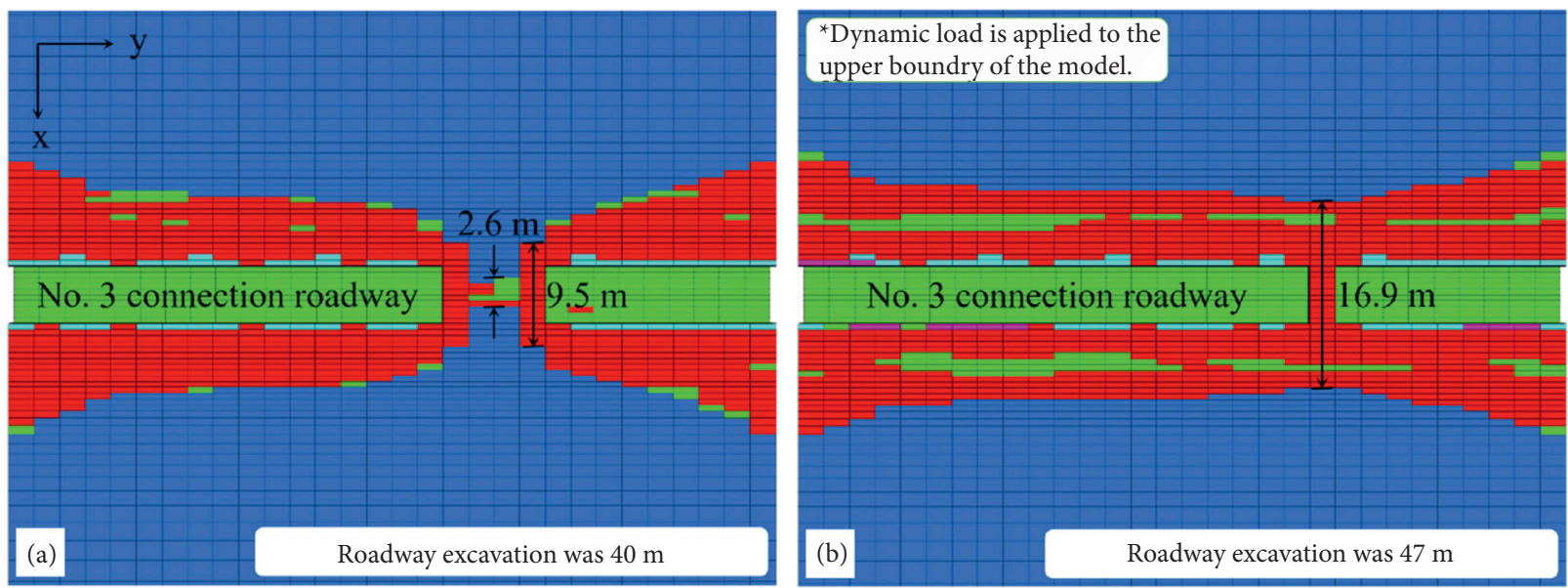

FIGURE 11: Distribution of surrounding rock plastic zone along the direction of excavation. Roadway excavation was (a) $40 \mathrm{~m}$ and (b) $47 \mathrm{~m}$.

which is close to the plastic zone range of the excavated and supported roadway. Overall, the plastic failure of the roadway roof mainly occurs within the $3 \mathrm{~m}$ range of the roof coal below the coal rock seam interface. With the connection of the roadway, the plastic zone of the roadway surrounding rock expands to the deep part of the two ribs as a whole. When there is a coal pillar of $3 \mathrm{~m}$, the support completely fails under the dynamic load disturbance.

In addition, to quantitatively analyze the temporal and spatial evolution law of the plastic zone of the overall roadway surrounding rock under dynamic disturbance, the numbers of failure zones on the roof, floor, and the two ribs of the roadway are respectively counted, as shown in Figure 12. It can be seen that the degree of plastic failure of the roadway floor is relatively light. As the roadway advances, the proportion of failure is slowly increasing, which is $3.7 \%$, $4.6 \%, 4.9 \%, 5.0 \%$, and $5.5 \%$, respectively. The degree of the two ribs failure is the second, and under the support of the ribs, the proportion of their failure has shown a more obvious decline as the roadway advances, followed by $46.2 \%$, $43.9 \%, 43.2 \%, 43.0 \%$, and $39.6 \%$. The degree of the roof is the most serious. As the roadway advances, its failure accounts for an increasing proportion, which is $50.1 \%, 51.5 \%, 51.9 \%$, $52.0 \%$, and $54.9 \%$, respectively. And within the last $7 \mathrm{~m}$ of advancing, the growth rate of the number of failure zones in the two ribs is $23.2 \%$, and the growth rate of the roof is as high as $41.4 \%$.

The whole process of excavation and support of deep rock burst drivage roadway shows that the plastic failure is mainly distributed in the roof coal and rock mass and the two ribs coal mass, and the floor rock mass has less plastic failure. Therefore, attention should be paid to strengthening the support strength of the roof and the two ribs when carrying out the support design. In addition, since the evolution of the roof sag pattern (as shown in Figure 7) shows a significant influence of the support scheme on the roof sag, it can be concluded that the "10.20" rock burst accident occurred because of the short length of the cable bolts that the top-coal cannot be effectively anchored in the stable key strata, and an effective bearing structure cannot be formed in the rock strata. The anchoring force and surface protection ability of the cable bolts alone cannot resist the disturbance of dynamic load in the high stress environment so as to ensure the stability of surrounding rock structure.

The analysis shows that the impact of dynamic load disturbance on the plastic deformation of the roof is greater than that on the two ribs and floor, and the plastic failure of the roof coal seam plays a leading role in the overall surrounding rock deformation of the roadway. 


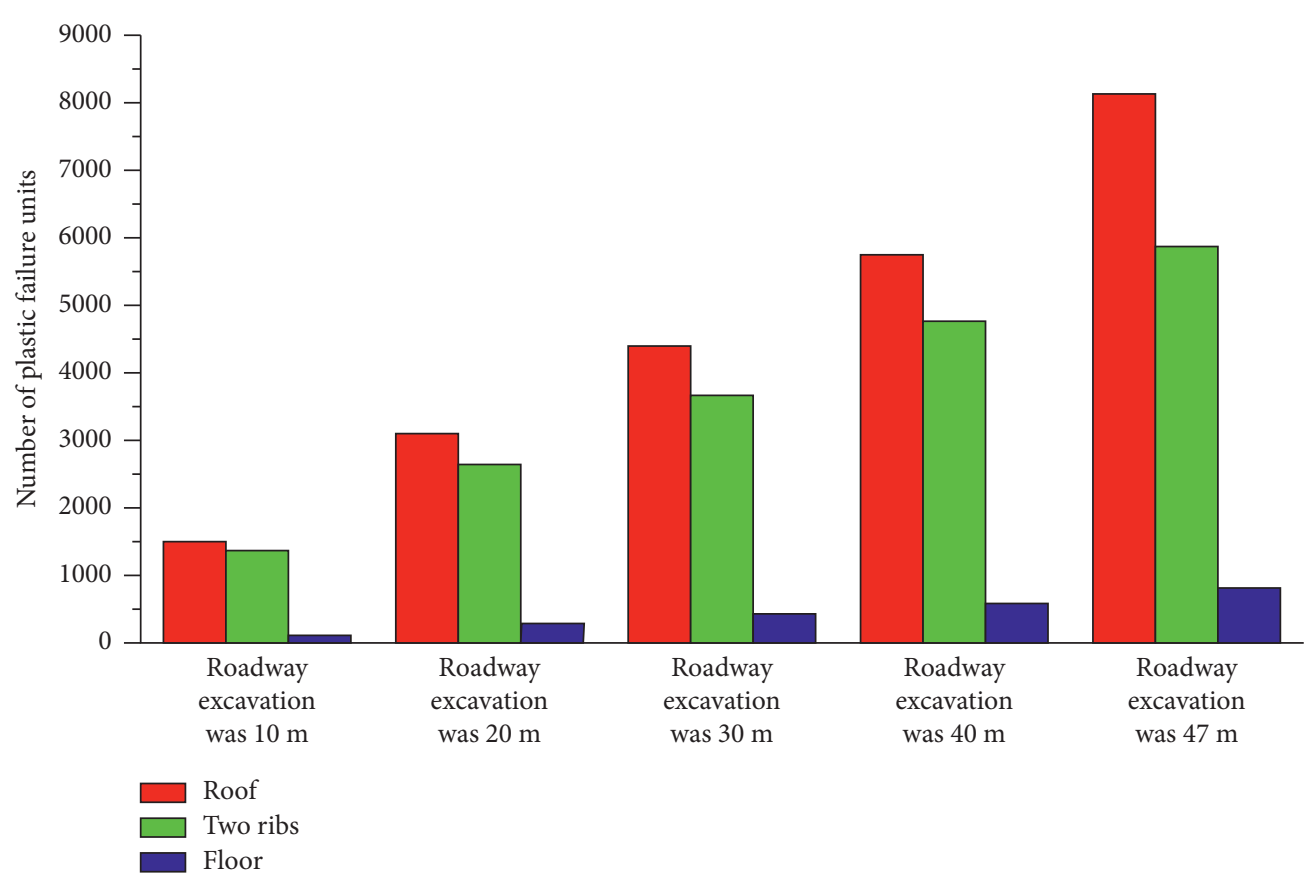

FIGURE 12: Evolution of surrounding rock plastic zone during roadway excavation.

3.4. Stress Field Evolution Law of Surrounding Rock under Dynamic Load Disturbance. In a high in situ stress environment, the roadway deformation and failure caused by dynamic disturbance are closely related to the stress transfer and redistribution of the surrounding rock, and the spatial distribution of the stress of the roadway surrounding rock and its evolution law have a significant impact on the deformation and failure characteristics of the surrounding rock. The large deformation and plastic failure of surrounding rock caused by deep rock burst drivage roadway all appear in the low stress area.

Figure 13 shows the stress distribution of surrounding rock along the direction of connection after the excavation of roadway. It can be seen from Figures 13(a) 13(d) that the stress area in the coal and rock mass between the heading face and the stop heading face presents a "low-high-low" distribution law before the roadway advances $10 \mathrm{~m}$ away, and the surrounding rock on the inner side of the high stress area and the heading face are in a low stress area. When it is $40 \mathrm{~m}$ away from roadway connection, the high stress area in front of the heading face is completely above $30 \mathrm{MPa}$, and therefore a small range of discontinuous stress peak area of $32.5 \sim 35 \mathrm{MPa}$ appears. When the distance of roadway connection is $30 \mathrm{~m}$, the high stress area of $30 \sim 32.5 \mathrm{MPa}$ in the coal and rock mass in front of it gradually expands along the advancing direction, and the $32.5 \sim 35 \mathrm{MPa}$ stress peak area continues to extend forward and appear continuous trend with the advancement of the heading face. When the distance of roadway connection is $20 \mathrm{~m}$, the range of the stress area of 30 32.5 MPa expands and superimposes rapidly, and the stress zone of $32.5 \sim 35 \mathrm{MPa}$ has become a continuous envelope and continues to extend along with the advancement of the heading face. When the distance of roadway connection is $10 \mathrm{~m}$, as shown in Figure 13(d), the peak stress area in front of the two heading face fronts is completely superimposed, during which the coal pillar reaches the peak strength, and the peak stress reaches 37.9 MPa. Finally, when the distance of roadway connection is $3 \mathrm{~m}$, dynamic load is applied to the upper boundary of the model, as shown in Figure 13(e), the high stress area of the $3 \mathrm{~m}$ coal pillar between the two heading faces completely disappears, and the coal pillar is destroyed. During this period, the stress value rapidly decreased to below $5 \mathrm{MPa}$, that is, the residual strength of the coal and rock mass after the peak. At the same time, the coal and rock mass in a certain range around the heading face and the roadway is also completely in the stress reduction zone, and it is very easy to lose stability under the disturbance. As a result, the plastic zone of the coal pillar and its surrounding rock rapidly develops and expands, and the overall bearing capacity of the surrounding rock decreases, which eventually induces rock burst accident. It can be judged from this that the support scheme does not have a significant support effect in terms of the results of the control of the roadway surrounding rock, especially the ability to resist dynamic disasters is poor.

\section{Analysis on the Mechanism of the "10.20" Rock Burst Accident of Longyun Coal Industry}

Underground activities, such as deep drivage disturbance and far-field focus disturbance, inevitably affect the coal and rock system around the roadway and make its stability change. The drivage disturbance will cause the local stress concentration and change the stress distribution in the surrounding coal and rock, so that the coal and rock in a certain range around the roadway will enter the plastic stage 


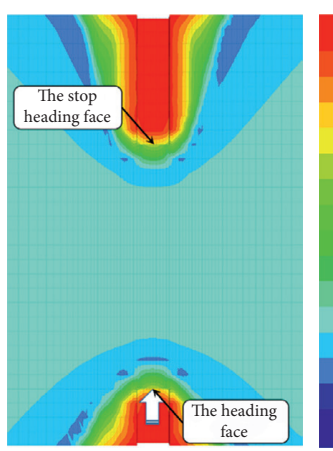

(a)

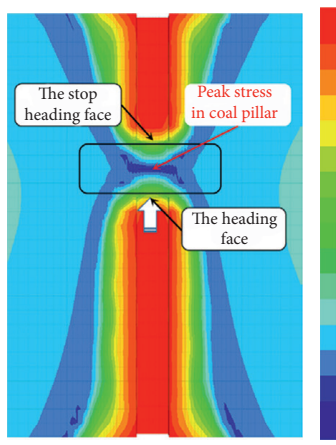

(d)
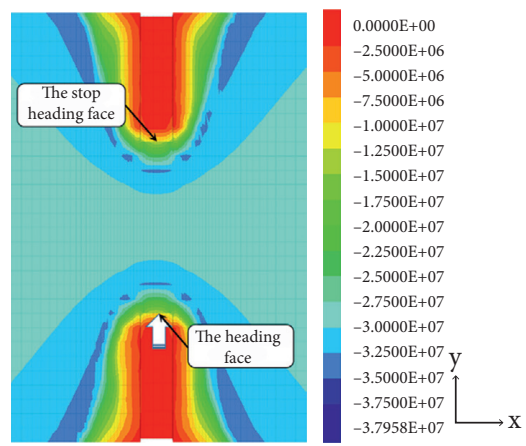

(b)

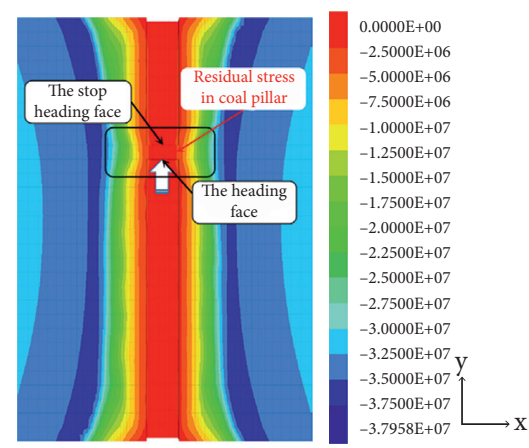

(e)

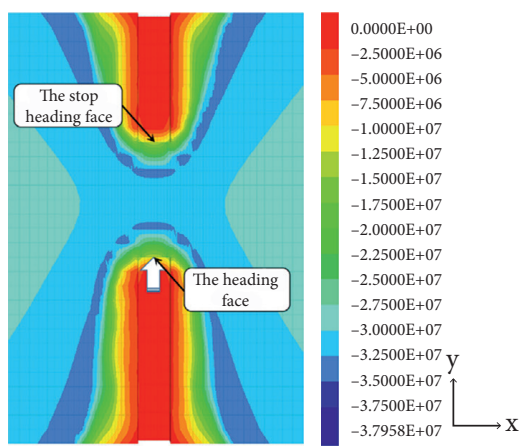

(c)

FIGURE 13: Distribution of surrounding rock stress along the direction of excavation. Roadway excavation was (a) $10 \mathrm{~m}$, (b) $20 \mathrm{~m}$, (c) $30 \mathrm{~m}$, (d) $40 \mathrm{~m}$, and (e) $47 \mathrm{~m}$.

and form the strain-softening zone, while the coal and rock in the deep is still in the elastic stage. In this way, the coal and rock system will be composed of the strain-softening zone composed of unstable surrounding rock and the elastic zone composed of stable surrounding rock, which will be in an unsteady state and easily destabilize under the disturbance of dynamic load. Therefore, for the coal and rock system in deep underground roadway, the formation of sufficient strain-softening zone and a certain range of elastic zone under the action of high stress will cause rock burst; that is, high load is the basis of rock burst.

Combined with site of Longyun Coal Industry "10.20" accident and the results of numerical simulation, the Longyun coal mine 1303 working face are the static load conditions of high stress concentration; meanwhile, separation and fracture of strata structure are caused by dynamic load conditions. The failure forms of the accident roadway mainly show the comprehensive failure characteristics such as the constriction of two ribs, roof subsidence, and caving. Among them, the roof of the roadway was seriously damaged, showing a large range of roof falling and collapse, the roof anchor cables were torsional and bent, some cable bolts had obvious new cracking traces, and some trays and nuts were still on the bolts body. The bolt body is in a bending state without obvious tension and necking, which indicates that the bolt is mainly subjected to horizontal load at the moment of roadway failure. The top-coal is mainly deformed by crushing under horizontal load. It can be inferred that the main reason for the top-coal caving is that the upper part of the roadway is a composite roof with joint development composed of top-coal and mudstone. At the moment of impact vibration damage, the top-coal of the roadway is broken and deformed under the impact load, and it cannot be effectively constrained due to the limited length of the anchor and the insufficient anchoring force of the cable. Moreover, the rock burst occurred during the coalesce of the roadway, and the buried depth of the accident area was about $1035 \mathrm{~m}$. The coal and rock are in the high-stress environment, and the regional stress adjustment and local high stress concentration are caused by the factors of mining activities and roadway close to breakthrough. Under the condition of high stress concentration, coal and rock are prone to dynamic disaster when disturbed by external load.

From the direct and indirect causes of rock burst accidents mentioned above, it can be seen that the superposition of high in situ stress and dynamic load disturbance is the main force source of rock burst and roof collapse caused by deep drivage, in which high in situ stress provides the source of static load, while driving disturbance increases the concentration of static load, and seismic source disturbance provides the source of dynamic load.

\section{Conclusion}

(1) Different from the general rotary or extrusion failure of the roof in deep roadway, the top-coal in deep rock burst drivage roadway is in the form of "inverted trapezoidal" subsidence. For the deep coal roadway with significant large deformation characteristics, its two ribs produce large deformation and plastic 
failure, and gradually expand to the deep of the surrounding rock, and finally reach a new equilibrium. In this process, the top-coal of the roadway is separated from the roof to relieve pressure, and the stress is transferred to the two ribs of the roadway, resulting in stress concentration. The shoulder angle of the roadway also has obvious subsidence, which leads to the overall significant subsidence of the topcoal of the roadway. In addition, it is easy to induce catastrophic damage such as roof caving and rock burst under the action of seismic source disturbance.

(2) The coal pillar between the two heading faces shows superposition of high-stress zone along with the penetration of roadway. When the distance between the two heading faces is $10 \mathrm{~m}$, the coal between the two heading faces has undergone advanced connection of plastic zone. Moreover, when the distance from linkage is $3 \mathrm{~m}$, the influence of dynamic load disturbance on the plastic deformation of roadway roof is greater than that on the two ribs and floor, and the plastic failure of roof coal seam plays a leading role in the deformation of roadway surrounding rock.

(3) For deep rock burst drivage roadway, if the bolt length is limited or the anchoring force of the cable is not enough to effectively restrain the top-coal, then under the dynamic load disturbance, roof separation, roof caving, and even rock burst accidents are easy to occur. Therefore, for this type of roadway, the roof should be strengthened to improve the bearing capacity of the top-coal.

\section{Data Availability}

The data used to support the findings of this study are available from the corresponding author upon request.

\section{Conflicts of Interest}

The authors declare that they have no conflicts of interest.

\section{Acknowledgments}

This study was financially supported by the National Natural Science Foundation of China (nos. 52074166 and 51774195) and the China Postdoctoral Science Foundation (2019M652436).

\section{References}

[1] H. Xie, F. Gao, Y. Ju et al., "Quantitative definition and analysis of deep mining," Journal of China Coal Society, vol. 40, no. 01, pp. 1-10, 2015.

[2] Q. Qi, Y. Li, S. Zhao et al., “The 70 Years development of coal mine rock burst in China: the establishment and thinking of theory and technology system," Coal Science and Technology, vol. 47, no. 9, pp. 1-40, 2019.

[3] J. He and L.-m. Dou, "Gradient principle of horizontal stress inducing rock burst in coal mine," Journal of Central South University, vol. 19, no. 10, pp. 2926-2932, 2012.
[4] L. Wang, Z. Lu, and Q. Gao, "A numerical study of rock burst development and strain energy release," International Journal of Mining Science and Technology, vol. 22, no. 5, pp. 679-684, 2012.

[5] M. Gao, Y. Zhao, and Y. Wen, "Energy criterion and practice of rock burst destructive force of seismic source disturbance type roadway," Journal of China Coal Society, vol. 41, no. 4, pp. 808-841, 2016.

[6] X. Li, J. Liao, G. Zhao, Z. Zhou, and Y. Zhou, "Dynamic response law of surrounding rock of high stress roadway under dynamic disturbance," Science and Technology Review, vol. 30, no. 22, pp. 48-54, 2012.

[7] X. Li and F. Gong, "Research progress and prospect of rock mechanics in deep mining based on static-dynamic coupling loading mechanical tests," Journal of China Coal Society, vol. 46, no. 3, pp. 846-866, 2021.

[8] P. Kong, L. Jiang, J. Jiang, Y. Wu, L. Chen, and J. Ning, "Numerical analysis of roadway rock burst hazard under superposed dynamic and static loads," Energies, vol. 12, no. 19, p. $3761,2019$.

[9] Z. Wang, L. Dou, and G. Wang, "Study on failure mechanism of rebar bolt support structure in circular roadway under dynamic load," Chinese Journal of Geotechnical Engineering, vol. 37, no. 10, pp. 1901-1909, 2015.

[10] K. Zhang, "Study on rock burst mechanism of mining roadway under coupling condition of structure and superthick conglomerate," Chinese Journal of Rock Mechanics and Engineering, vol. 36, no. 4, p. 1040, 2017.

[11] H. Li, H. Bai, D. Ma, C. Tian, and Q. Zhang, "Simulation study of floor rock fracture evolution law under mining dynamic load," Journal of Mining and Safety Engineering, vol. 35, no. 2, pp. 366-372, 2018.

[12] J. Ning, P. Qiu, S. Yang, Z. Shen, Z. Li, and J. Wang, "Damage mechanism and support of surrounding rock anchorage structure of deep large section chamber under static-dynamic coupling loading," Journal of Mining and Safety Engineering, vol. 37 , no. 1 , pp. 50-61, 2020.

[13] H. Kang, "Temporal scale Analysis on coal mining and strata control technologies," Journal of Mining and Strata Control Engineering, vol. 4, no. 1, pp. 1-26, 2021.

[14] H. Kang, G. Xu, B. Wang et al., "Forty years development and prospects of underground coal mining and strata control technologies in China," Journal of Mining and Strata Control Engineering, vol. 1, no. 2, pp. 7-39, 2019.

[15] W. Zhu, L. Niu, S. Li, and S. Li, "Creep-impact test of rock: status-of-the-art and prospect," Journal of Mining and Strata Control Engineering, vol. 1, no. 2, pp. 77-87, 2019.

[16] F. Gao, X. Gao, and H. Kang, "FLAC analysis of mechanical response of surrounding rock mass in deep tunnel," Chinese Journal of Underground Space and Engineering, vol. 5, no. 4, pp. 680-685, 2009.

[17] G. Wang, J. Yao, Y. Wang, and X. Song, "Numerical analysis of mechanical response of deep roadway group under dynamic disturbance," Coal Technology, vol. 33, no. 4, pp. 98100, 2014.

[18] L. Tang, L. Gao, C. Wang, and F. Jiang, "Mechanical response features of roadway surrounding rock with weak interlayer under dynamic disturbance," Science and Technology Review, vol. 32, no. 21, pp. 56-61, 2014.

[19] L. Tang, L. Gao, C. Wang, and F. Jing, "Numerical analysis of stability of roadway surrounding rock with weak interlayer under dynamic disturbance," Journal of Mining and Safety Engineering, vol. 33, no. 1, pp. 63-69, 2016. 
[20] Y. Yuan, W. Wang, C. Yuan, W. Yu, H. Wu, and W. Peng, "Large deformation failure mechanism of surrounding rock for gateroad under dynamic pressure in deep coal mine," Journal of China Coal Society, vol. 41, no. 12, pp. 2940-2950, 2016.

[21] Y. Wu, J. Chen, J. Jiao, Y. Zheng, and J. He, "Damage and failure mechanism of anchored surrounding rock with impact loading," Journal of China Coal Society, vol. 43, no. 9, pp. 2389-2397, 2018.

[22] J. Jiao, W. Ju, Y. Wu, and J. He, "Multi-layer control technologies for surrounding rock stability of dynamic-loading rock burst roadway," Coal Science and Technology, vol. 47, no. 12, pp. 10-17, 2019.

[23] J. Jiao, "Analysis on influencing factors of stability of anchorage bearing structure of roadway under dynamic load," Journal of Henan Polytechnic University, vol. 40, no. 4, pp. 19-27, 2021.

[24] C. Li, Y. Zhang, G. Zhang, S. Gao, and H. Wang, "Crack propagation mechanisms and stress evolution of floor under dynamic disturbance in deep coal mining," Chinese Journal of Geotechnical Engineering, vol. 40, no. 11, pp. 2031-2040, 2018.

[25] H. Jing, J. Wu, Q. Yin, X. Shi, and Z. Zhao, "Particle flow simulation of rock burst and roof fall of deep coal roadway under dynamic disturbance," Chinese Journal of Rock Mechanics and Engineering, vol. 39, no. S2, pp. 3475-3487, 2020.

[26] Bureau of Shandong coal mine safety supervision, Investigation Report of Shandong Longyun Coal Industry Co., Ltd. '10.20' Major Rock Burst Accident, Bureau, Shandong, China, 2019.

[27] G. Ren, "Large mining depth and high stress, high risk of rock burst; shallow cognition and sparse prevention, heavy casualties in concentration: analysis of the ' 10.20 ' major accident of Shandong Longyun coal Industry," Jilin Labor Protection, vol. 3, no. 4, pp. 41-43, 2019.

[28] J. He, L. Dou, S. Wang, and C. Shan, "Study on mechanism and types of hard roof inducing rock burst," Journal of Mining and Safety Engineering, vol. 34, no. 6, pp. 1122-1127, 2017.

[29] W. Zhu, Z. Li, L. Zhu, and C. A. Tang, "Numerical simulation on rockburst of underground opening triggered by dynamic disturbance," Tunnelling and Underground Space Technology, vol. 25, no. 5, pp. 587-599, 2010. 